\title{
Early intervention in pertussis outbreak with high attack rate in cohort of adolescents with complete acellular pertussis vaccination in Valencia, Spain, April to May 2015
}

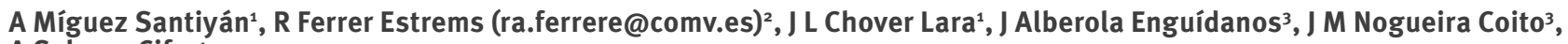 \\ A Salazar Cifre ${ }^{1}$ \\ 1. Epidemiology Department, Public Health Centre of Valencia (DGSP), Valencia, Spain \\ 2. Preventive Medicine Department, Consorcio Hospital General Universitario de Valencia, Valencia, Spain \\ 3. Microbiology Department, Hospital Universitario Dr. Peset, Valencia, Spain
}

Míguez Santiyán A, Ferrer Estrems R, Chover Lara JL, Alberola Enguídanos J, Nogueira Coito JM, Salazar Cifre A. Early intervention in pertussis outbreak with high attack rate in cohort of adolescents with complete acellular pertussis vaccination in Valencia, Spain, April to May 2015. Euro Surveill. $2015 ; 20(27)$ :pii=21183. Available online: http://www.eurosurveillance.org/ViewArticle.aspx?Articleld=21183

Forty-three pertussis cases reported in May 2015 in Valencia were linked to a school outbreak where $90 \%$ of the students had been vaccinated. Cases were diagnosed upon paediatrician consultation and in hospital emergency units. Approximately half of the cases were students born in $\mathbf{2 0 0 2}$, the first age cohort with complete shift to acellular pertussis vaccine. Public health intervention, visiting school premises to conduct interviews, sample collection and early antibiotic prophylaxis stopped further spread in the community.

\section{Event description}

In early May 2015, two suspected cases of pertussis in twins raised the alert in a school in Valencia, Spain. On 6 May, the school headmaster contacted the local public health authorities to report other students with persistent cough. A team of epidemiologists performed an investigation at the school premises on the following day, as a pertussis outbreak was suspected. During two further visits within the coming four days, the team detected a high incidence of pertussis cases among students in the first grade of secondary school, born in the years 2001 and 2002, including 10 laboratoryconfirmed cases. Rapid risk assessment guided further intervention to tackle the spread of the disease.

\section{Epidemiological investigation}

The epidemiology units in the Valencian Community are responsible to monitor and respond to alerts from a computerised mandatory notification system (AVE, Análisis de Vigilancia Epidemiológica) and from laboratories in public hospitals (RedMiva, Red de Vigilancia Microbiológica de la Comunidad Valenciana). Epidemiologists also have access to the primary healthcare (PHC) computer system (SIA, Sistema de Información Ambulatoria) and to the vaccine information system (SIV, Sistema de Información Vacunal). During the outbreak described here, the overall surveillance system (individual systems are described on the website of the General Directorate of Public Health of Valencian Community [1]) allowed daily identification and follow-up of notified cases.

Information on the type and duration of treatment, on the date of symptom onset, on disease evolution, number of vaccine doses administered, was entered in the AVE which was used as database for this outbreak investigation.

\section{Case definition}

For the outbreak investigation, an adapted version of the Spanish case definition for pertussis was used [2]. The notified cases in the AVE were defined as 'laboratory-confirmed' (if PCR or serology were positive) or as 'epidemiologically-linked' when having clinical symptoms compatible with pertussis and history of contact with a laboratory-confirmed case. Individuals who did not fulfil the criteria above were dismissed as 'noncases'. For notification purposes, all initial probable cases were re-defined when included in AVE as 'epidemiologically linked'.

\section{Case investigation}

The epidemiology unit team from Valencia assessed the situation at school premises, among the 395 students and 47 teachers. They conducted interviews with 50 symptomatic students, after having received verbal consent from their parents, and five teachers; in addition, they collected microbiological samples (nasopharyngeal smears) to confirm the outbreak that reached a total of 43 cases. The majority of the cases was fully vaccinated (Table). 
Number of cases by date of symptom onset, pertussis school outbreak, Valencia, Spain, April-May 2015 (n=43)

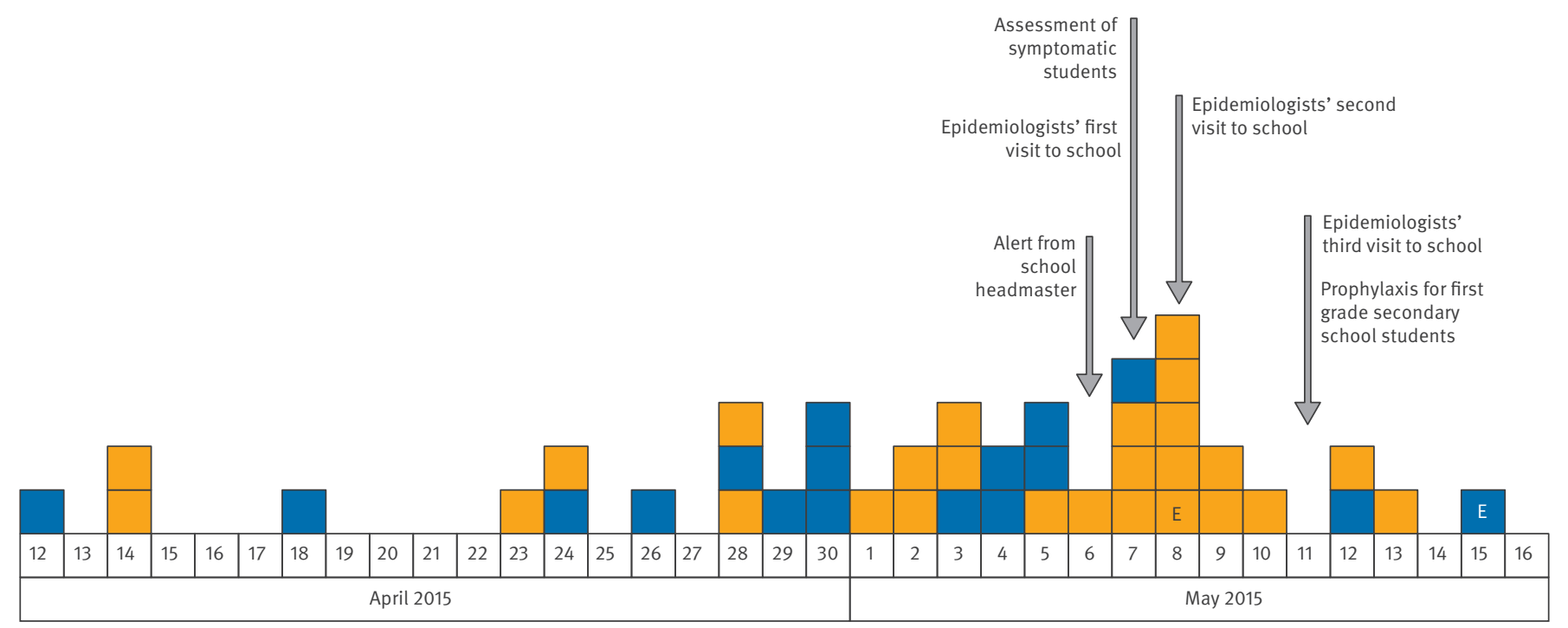

Laboratory-confirmed

Epidemiologically linked
E External cases (not attending the same school)
Among the 43 cases, 40 were students and one was a school teacher; there were two additional cases, in other students who shared common after-school activities, and were thus classified as 'epidemiologically linked' cases. Among school students just over half of the cases were in males and median age was 13 years, ranging from 12 to 17 years. Information on vaccination coverage was available for grades in which cases occurred: 243 of 275 (88.4\%) children in these grades were vaccinated with at least four doses; $89.4 \%$ (67/75) vaccination coverage was recorded in students in the first grade of secondary school; $95.2 \%$ (40/42) of student cases had been vaccinated, of which $90.4 \%$ had been fully vaccinated with five doses.

Here, we describe the evolution of the outbreak cases according to the date of symptom onset (Figure 1).

The investigation confirmed a higher attack rate (37\%) in students the first grade of secondary school (28/75), of which 23 were born in 2002, the first age cohort with complete shift to acellular pertussis vaccine in our region (Figure 2 ).

In 2008, the last pertussis vaccination dose was administered in the 2002 cohort.

\section{Control measures}

After confirmation of the outbreak, students, staff, parents, local GPs and paediatricians were informed about it either directly by telephone or by a letter given to the school's headmaster to give to children's parents. In an initial stage, all symptomatic children were referred to their paediatricians for diagnostic and treatment with recommendations from the public health authorities to undertake antibiotic treatment, delay return to school until after completion of treatment, and follow up and prophylaxis of close contacts. As new cases were confirmed, decision was taken to extend prophylaxis to all students in the first grade of secondary school, with recommendation to treat with azithromycin for five days (500 $\mathrm{mg}$ on the first day and $250 \mathrm{mg}$ on the following days) [2]. In addition to antibiotic treatment, they were recommended isolation for five days and vaccination if they had not completed five doses. Following these recommendations, 63 of the first grade students had received prophylactic antibiotic treatment. There was additionally an active investigation to identify risk groups, (pregnant women and infants under one year old), but the team did not identify any of them among contacts linked to outbreak cases.

\section{Epidemiological context}

Pertussis shows a characteristic cyclic pattern peaking every three to four years. In recent years, an increase in the number of cases has been noticed in different European countries, including Spain, in spite of good vaccination coverage [3,4]. Studies have also indicated a decline in antigenic response to acellular vaccine already few years after vaccination booster and 
FIGURE 2

Attack rate by age cohort, pertussis school outbreak, Valencia, Spain, April-May $2015\left(\mathrm{n}=40^{\mathrm{a}}\right)$

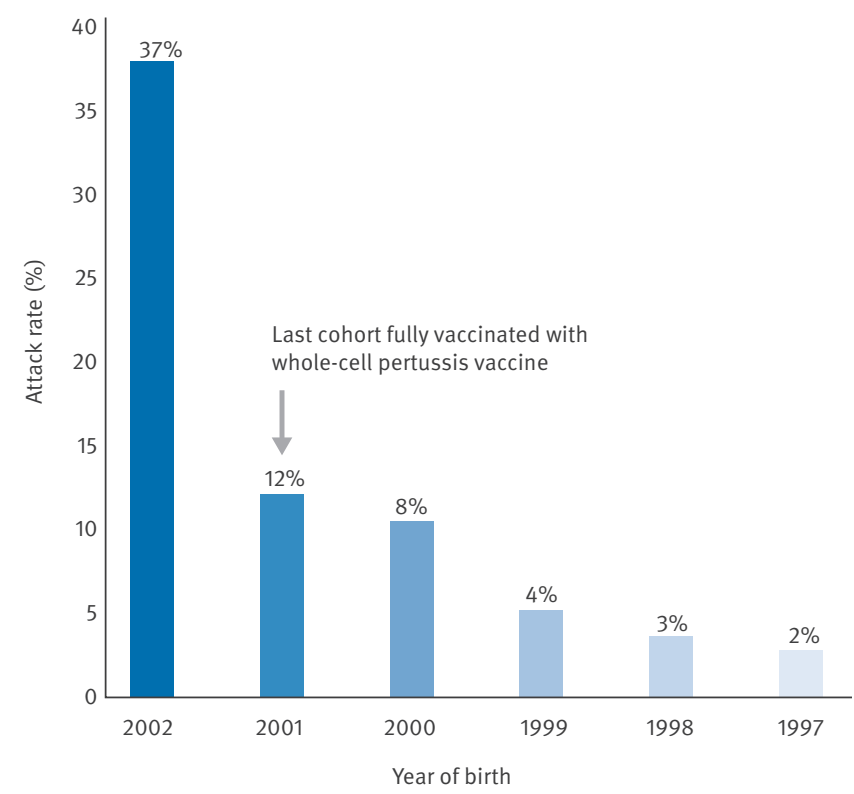

a One teacher and two external cases not included.

\section{TABLE}

Description of cases and vaccination coverage, pertussis school outbreak, Valencia, Spain, April-May $2015(\mathrm{n}=43)$

\begin{tabular}{|c|c|c|}
\hline & & Number \\
\hline \multirow{2}{*}{ Sex } & Men & 24 \\
\hline & Women & 19 \\
\hline Age (years $\left.{ }^{a}\right)$ & \multicolumn{2}{|c|}{ Median (range) $13(12-17)$} \\
\hline \multirow{3}{*}{ Case classification } & Students & 40 \\
\hline & Teachers & 1 \\
\hline & External cases & 2 \\
\hline \multirow{4}{*}{ Case confirmation } & Laboratory & 17 \\
\hline & PCR & 15 \\
\hline & Serology & 2 \\
\hline & Epidemiological & 26 \\
\hline \multirow{5}{*}{$\begin{array}{l}\text { Vaccination with } \\
\text { pertussis vaccine }\end{array}$} & Yes & 40 \\
\hline & Complete $^{b}$ & 38 \\
\hline & Incomplete & 2 \\
\hline & No & 1 \\
\hline & Not recorded & 2 \\
\hline
\end{tabular}

a Students only, one teacher aged $>45$ years not included here.

bive doses. this could result in the near future in vulnerable age cohorts vaccinated exclusively with it $[5,6]$. This highlights that even a full course of acellular vaccine in line with the present vaccination schedules and good coverage may not confer sufficient protection to adolescents, and that there continues to be a risk of epidemic waves each three to four years $[7,8]$.

In Spain, the vaccination schedules for pertussis vary little among regions, with doses given at 2-4-6 and 18 months and a booster at five to six years of age. Only two regions have included a sixth booster dose at 14 years of age, although most paediatricians suggest a booster for 11-12 year-old children [9]. The type of vaccine changed in the Valencian Community since 2001 for the booster dose, when acellular vaccine was included in the programme. It completely replaced the cellular vaccine also for the first doses in 2004. In practical terms this last substitution was implemented for birth cohorts 2002 and 2003.

\section{Discussion}

During April and May 2015, we have seen an increase of pertussis cases in the city of Valencia, which follows the cyclic pattern of pertussis. The last pertussis epidemic had occurred in 2011 and led to 249 cases in 12 months [10]. Incidence in 2015 has surpassed, up to 6.5 times during week 22, the expected number of cases in a normal season for Valencian Community as a whole [11]. In the city, this seemingly seasonal [12] manifestation clearly has increased incidence and transmission in school children and has presented in form of small outbreaks in primary and secondary educational institutions (age 9 to 13 years) besides the one described in this communication. In these outbreaks prophylactic early intervention in close contacts (same class) have been crucial in stopping further transmission. The rapid intervention in this outbreak has achieved an interruption of transmission within two weeks of implementation of control measures with a last case reported on 28 May, only two cases of onward transmission to community members outside the affected school were noted and no cases were detected in vulnerable individuals.

In general, the awareness of a situation with susceptible individuals has triggered other vaccination strategies like cocooning or more recently to expand vaccination to pregnant women [13-15]. The Valencian Community has implemented such changes too [16].

\section{Conclusions}

Our investigation highlights the potential increased risk in the first age cohorts with complete vaccination with acellular pertussis. This is consistent with the results of other studies where risk is seen to increase three years after the last acellular dose [5]. These findings should be incorporated into vaccination strategies decisions and they should promote research on new anti-pertussis vaccine components with greater effectiveness and longer protection. Experience with this 
early intervention brings evidence that rapid response to public health alerts after suspicion of pertussis cases allows early diagnosis and intervention to stop transmission to core vulnerable groups (i.e. pregnant women and children under one year of age).

\section{Acknowledgments}

We want to acknowledge all Primary Health Care family doctors and paediatricians in Valencia City for their contribution to early detection and follow-up of cases.

\section{Conflict of interest}

None declared.

\section{Authors' contributions}

Ana Míguez Santiyán: Public health intervention in school, cases' identification, sample collection and follow up; notification of cases and data collection; inclusion in the regional system for Analysis of Epidemiological Surveillance; recommendations for management of cases and contacts based on Spanish national guidelines to children and staff; data base development and data analysis; figures and tables; article writing and review.

Rafael Ferrer Estrems: Public health intervention in school, cases' identification, sample collection and follow up; database development and data analysis; figures and tables; literature review and bibliography preparation; article writing and editing.

Jose Luis Chover Lara: Public health intervention in school, cases' identification, sample collection and follow up; notification of cases and data collection; inclusion in the regional system for analysis of epidemiological surveillance; recommendations for management of cases and contacts based on Spanish national guidelines to children and staff; article review.

Juan Alberola Enguídanos: laboratory samples processing; diagnostic and notification of laboratory results; article review.

Jose Miguel Nogueira Coito: Laboratory samples processing; diagnostic and notification of laboratory results; article review.

Antonio Salazar Cifre: Public health intervention in school, cases' identification, sample collection and follow up; notification of cases and data collection; inclusion in the regional system for analysis of epidemiological surveillance; recommendations for management of cases and contacts based on Spanish national guidelines to children and staff; article review.

\section{References}

1. Generalitat Valenciana. Conselleria de Sanitat. Dirección General de Salud Pública. [General Directorate of Public Health]. Valencia: Generalitat Valenciana. [Accessed 9 Jul 2015]. Spanish. Available from: http://www.sp.san.gva.es

2. Centro Nacional de Epidemiología. Instituto de Salud Carlos III. Red Nacional de Vigilancia Epidemiológica. Protocolos de enfermedades de declaración obligatoria. [Protocol for diseases with mandatory notification]. Madrid, 2013. [Accessed 9 Jul 2015]. Spanish. Available from: http://www. isciii.es/ISCIII/es/contenidos/fd-servicios-cientifico-tecnicos/ $\mathrm{fd}$-vigilancias-alertas/PROTOCOLOS_RENAVE.pdf

3. World Health Organization (WHO). WHO SAGE pertussis working group. Background paper. SAGE April 2014. Geneva: WHO. [Accessed 9 Jul 2015]. Available from: http://www.who. int/immunization/sage/meetings/2014/april/1_Pertussis background_FINAL4_web.pdf
4. Sizaire V, Garrido-Estepa M, Masa-Calles J, Martínez de Aragon MV. Increase of pertussis incidence in 2010 to 2012 after 12 years of low circulation in Spain. Euro Surveill. 2014;19(32):20875. http://dx.doi.org/10.2807/1560-7917. ES2014.19.32.20875 PMID:25139074

5. Aase A, Herstad TK, Jørgensen SB, Leegaard TM, Berbers G, Steinbakk M, et al. Anti-pertussis antibody kinetics following DTaP-IPV booster vaccination in Norwegian children 7-8 years of age. Vaccine. 2014;32(45):5931-6. http://dx.doi. org/10.1016/j.vaccine.2014.08.069 PMID:25218299

6. Witt MA, Katz PH, Witt DJ. Unexpectedly limited durability of immunity following acellular pertussis vaccination in preadolescents in a North American outbreak. Clin Infect Dis. 2012;54(12):1730-5. http://dx.doi.org/10.1093/cid/cis287 PMID:22423127

7. Aizpurua $P$, Rivas MA. ¿Hay relación entre los últimos brotes de tosferina y el uso de vacuna acelular? [Is there any connection between the recent pertussis outbreaks and the use of acellular vaccine?]. Evid Pediatr. 2013;9:69. Spanish.

8. Sheridan SL, Ware RS, Grimwood K, Lambert SB. Number and order of whole cell pertussis vaccines in infancy and disease protection. JAMA. 2012;308(5):454-6. http://dx.doi. org/10.1001/jama.2012.6364 PMID:22851107

9. Moreno-Pérez D, Álvarez García FJ, Arístegui Fernández J, Cilleruelo Ortega MJ, Corretger Rauet JM, García Sánchez N, et al.; en representación del Comité Asesor de Vacunas de la Asociación Española de Pediatría (CAV-AEP). [Immunisation schedule of the Spanish Association of Paediatrics: 2015 recommendations]. An Pediatr (Barc). 2015;82(1):44.e1-12. PMID:25554656

10. Generalitat Valenciana. Dirección General de Salud Pública. Subdirección general de epidemiología y vigilancia de la salud. Servicio de Vigilancia y Control Epidemiológico. Tos ferina. Vigilancia Epidemiológica año 2011. [Whooping cough. Epidemiological surveillance 2011]. Spanish. Available from: http://www.sp.san.gva.es/DgspPortal/docs/Tosferina_2011. pdf

11. Generalitat Valenciana. Conselleria de Sanitat. Dirección General de Salud Pública. Subdirección general de epidemiología y vigilancia de la salud. Análisis epidemiológico semanal. [Weekly epidemiological analysis]. Spanish. Available from: http://www.sp.san.gva.es/DgspPortal/docs/semana_ cas.pdf

12. Wang K, Fry NK, Campbell H, Amirthalingam G, Harrison TG, Mant D et al, Whooping cough in school age children presenting with persistent cough in UK primary care after introduction of the preschool pertussis booster vaccination: prospective cohort study. BMJ. 2014;348:93668foi:10.1136/ bmj.g3668

13. Amirthalingam G, Andrews N, Campbell H, Riberior S, Kara $\mathrm{E}$, Donegan K et al. Effectiveness of maternal pertussis vaccination in England: an observational study. Lancet. 384:1521-1528. Oct 25.2014.

14. Mooi FR, de Greeff SC. The case for maternal vaccination against pertussis. Lancet Infect Dis. 2007;7(9):614-24. http:// dx.doi.org/10.1016/S1473-3099(07)70113-5 PMID:17537674

15. Amirthalingam G. Strategies to control pertussis in infants. Arch Dis Child. 2013;98(7):552-5. http://dx.doi.org/10.1136/ archdischild-2012-302968 PMID:23698594

16. Dirección General de Salud Pública. Conselleria de Sanitat. Generalitat Valenciana. Vacunación de las embarazadas frente a la tos ferina en la Comunidad Valenciana. [Vaccination of pregnant women against pertussis in Valencian Community]. Spanish. Available from: http://www.sp.san.gva.es/ DgspPortal/docs/VACUNACION_DE_LAS_EMBARAZADAS FRENTE_TOS_FERINA_CCVV.pdf 